\title{
EDUCATING NURSES TO DELIVER OPTIMUM CARE TO MILITARY VETERANS AND THEIR FAMILIES
}

\begin{abstract}
The aim of the project was to help prepare the future nursing workforce to provide optimum care for the Armed Forces Community.

Structured evidenced-based educational sessions were designed and then delivered at two Universities in England. This educational model included a flipped approach, didactic classroom teaching, blended learning, and information technology.
\end{abstract}

Educational sessions were provided to 468 first year Bachelor of Nursing undergraduate students in 2017 and 2018. A mixed methods evaluation included a quasi-experiential design with pre and post-test data followed by research interviews conducted by student nurses and analyzed using a modified Grounded Theory.

Post session evaluation demonstrated a significant improvement in students' knowledge. 93\% agreed that the training was useful, $95 \%$ felt that nurses should be aware of the healthcare needs of the Armed Forces Community, and $89 \%$ indicated that the subject matter should be included in the undergraduate curriculum. A qualitative theoretical model was built from four major clusters: the military community; student's identity, clinical engagement, and future practice.

These educational sessions are being introduced into a growing number of United Kingdom Universities to create future nursing leaders with a better insight into the large and diverse Armed Forces Community. 
Keywords Military Nursing; Defence Nursing; Nurse Education; Nursing Students 


\section{Introduction}

Service-personnel risk their lives in defence of their country, whilst their families are exposed to frequent changes in location and spend long periods apart. Many service-personnel witness horrendous events, including the death of friends, colleagues and civilians of all ages, which may result in Mental Health (MH) disorders (Gov UK, 2018). In the United Kingdom (UK), there is a growing focus on assisting veterans to handle adverse physical and MH difficulties related to their military career (Ministry of Defence (MOD), 2008, MOD 2015, National Health Service (NHS), 2017), whilst recognising the extensive demands placed on military personnel and their families during the campaigns in Iraq (2003-2011) and Afghanistan (2001-2014). However, there are no mandated under graduate nursing sessions that focus on the Armed Forces Community (AFC). To change this narrative, the University of Cxxx has introduced an innovative educational initiative to prepare student nurse to care for the AFC.

\section{Background}

Military veterans form a heterogeneous population that differ by factors such as age, gender, and length of service. They are embedded in the fabric of society, with UK veterans estimated at 2.4M (MOD, 2019; NHS Choices, 2018a), USA veterans at 20M (US Census Bureau, 2019), whilst Australia is unaware of the number in their veteran population (Australian Government, 2018). These figures can be multiplied by four to indicate the number of the wider AFC of serving personnel, veterans and their families (NHS Choices, 2018b).

There is an assertion that anyone who served in the armed forces is changed in some way (Coll et al, 2011), due to being mentally scarred by their military experiences (Wessely, 
2005), leading to a veteran population that are perceived as being more susceptible to $\mathrm{MH}$ problems (Ashcroft, 2017). Some veterans experience difficulty reintegrating into civilian life; facing housing, education, training and employment challenges (Mobbs \& Bonanno, 2018), with higher unemployment rates for both men and women than that of the general population (United States Department of Labor, 2014; Ashcroft, 2014). What is not readily acknowledged is that many transition into a civilian community in which they thrive (Hynes \& Thomas, 2016). Veterans are often unwilling to disclose problems associated with their former military life because they believe that civilians (including healthcare professionals) do not understand military culture and therefore cannot appreciate their individuality (Flowers et al, 2017).

UK veterans are entitled to priority NHS treatment for medical and mental conditions related to their military service (NHS Choices, 2018b), and NHS staff (including 639,000 nurses) need a detailed understanding of health and social issues associated with the AFC (Finnegan et al, 2017). Men in general are poor at seeking help (Yousaf et al, 2015), and this reluctance is amplified in the military veteran population when accessing any health support (Hines et al, 2014). A major barrier is stigma (Iversen et al, 2011), leading to the mistrust of health services and subsequent hiding of symptoms (Finnegan et al, 2014). They need better clinical support (Conrad et al, 2015) and one way is to provide a better-informed nursing workforce through the formal recognition of the requirement for a structured and systematic educational syllabus to address AFC's health and social needs.

In the US, there is acknowledgement that undergraduate students (Moss et al, 2015) and nurses have a vital part in supporting veterans (Miltner et al, 2013), In 2011, First Lady Michelle Obama and Dr Jill Biden launched a 'Joining Forces' initiative with the intent of 
producing a nursing and clinical workforce with the requisite clinical competencies to care for their veteran population. This led to 500 USA educational institutions committing resources and effort to improving the healthcare of the AFC (Elliott \& Patterson, 2017); with a particular emphasis on the family (McMillan et al, 2017; Rossiter, 2018). Subsequently, multiple USA initiatives were introduced and evaluated (Elliott, 2018), and care of the AFC is progressing to being formally embedded in the nursing curriculum (Allen et al, 2013). The broad range of educational programmes include a variety of teaching methodologies, resulting in a multi-faceted academic model that comprehensively addresses education, research, and employment initiatives (Elliott, 2018). The authors' intent is to translate elements of these US initiatives into a UK academic model.

\section{The Study}

\section{Aim}

To determine if an educational initiative will enable Bachelor of Nursing (BNurs) undergraduate students to gain an understanding and insight into the AFC of serving personnel, veterans and their families, and to increase knowledge of the specific biopsychosocial implications aligned to their care, health and wellbeing.

The objectives were that the students would:

- Acquire an awareness of the AFC and an understanding of the term 'military veteran'. 
- Obtain an appreciation of the communication skills / language required for engaging with the AFC.

- Recognise the key role that nurses, and other healthcare professionals, have in improving and promoting the physical and mental wellbeing of the AFC.

- Provide a balanced synopsis of the positive and negative factors associated with being a member of the AFC.

The authors completed a mixed methods evaluation to identify the impact of the session in regard to knowledge acquisition and identify the student's views regarding the importance of these sessions within undergraduate nurse training. The lessons were conducted between April 2017 and July 2018 at the Universities of Cxxx and Sxxx, England.

\section{Design of the Educational Sessions}

The initial preparation schedule was to define the educational requirement, theoretical position, lesson plan, and session content. The first author utilised a Winston Churchill Memorial Trust Fellowship Award to visit the USA. Engagement with the American Academy of Nursing and meetings with senior US academics and clinical staff provided an insight into their educational models for supporting veterans. This afforded an insight into how curriculum content was defined and programmes were: scoped and prepared; funded and costed; constructed; marketed; introduced into clinical experience; evaluated and lessons learnt. This visit offered an overview of US online courses, the technical interfaces for 
educational delivery and insight into what lessons could be translated into UK undergraduate nursing educational sessions.

\section{Methodology}

A mixed methods approach was selected. For the quantitative component, the intent was to determine the effectiveness of the training in terms of knowledge acquisition and a quasiexperimental methodology was chosen with pre and post-tests either side of the session. Questionnaires were used, as this method has been recognised as a useful data-collecting tool for gauging satisfaction, moods, and beliefs (Czaja \& Blair, 2005; Oppenheim, 1992).

Student answers and views were captured on questionnaires designed by the first author, with the questions constructed following consultation with clinical and non-clinical staff, service users and following published guidelines (Bisset \& Chessan, 2000). The post session quiz included an additional 11 evaluation questions. A five-point Likert scale was utilised to determine the students' views regarding relevance and attitudes towards the training.

For the qualitative element, the authors accept that the AFC generate their awareness from serving in different environments, such as peacetime posting in foreign countries or on operational tours. This lifestyle lends itself to a constructivist grounded theory (Charmaz, 2014), which recognise that insight and knowledge can be gained from a critical analysis of a participant's beliefs, thoughts and feelings. This reliable and valid methodological approach provides real time applied data to demonstrate how the research sample create their understanding of the world (Charmaz, 2014). The approach utilised was a modified Grounded Theory that included: constructing analytical codes and categories from the data and not from preconceived suppositions; using the constant comparative method to construct comparisons during each stage of the analysis, and memo-writing to elaborate between 
categories, specify their properties, define correlations and identify gaps. This methodology has been adopted by the majority of published UK Armed Forces qualitative research (Batham et al, 2012; Crawford et al, 2009; Finnegan et al, 2016a) and veteran samples (Finnegan, 2016b).

\section{Method}

The participants were a convenience cohort of 468 UK first year undergraduate student nurses based at two UK Universities in North West England. Three-hour educational sessions were to be presented within a stepped approach; one session was delivered in each of the students' three-year BNurs undergraduate training programme. The first sessions were presented to students who had completed at least six months of their first year. They were informed that there was no requirement for prior knowledge of the AFC. Preparation included a "flipped approach" voluntary assignment, with students invited to gather detail of a family member (grandad, sister, child etc.) who has served in the British Armed Forces. The intent being to stimulate connectivity with the subject; linking their family's military experiences to today's workforce requirements, and begin to develop an awareness of the AFC. The session included the aforementioned quiz, animations, vignettes, didactic presentations and blended learning.

At the beginning of the sessions, the students were invited to complete a 20 -question multiple choice AFC quiz. Each question offered at least four possible answers labelled A, B, C, D and occasionally E. One answer was correct, and the student chose the one they thought was right. The students submitted their answers via an app on their mobile phones, although this later changed to pen and paper due to financial reasons. Students were informed that the answers to the quiz would be disclosed during the presentations, and that near the end of the 
session the quiz would be revisited. The quiz questions included facts regarding the Armed Forces such as: population size, common military abbreviations, and military slang. Some students were veterans, yet those with little knowledge were offered the chance to engage and ask questions, and had an opportunity to build on their pre-course assignment and voluntarily share information about their relative's experiences. Discussion regarding the characteristics of AFC included the diversity and the role of ethnic minorities such as Victoria Cross winners from India, Jamaica, Ireland, and Nepal. Students explored factors related to the Armed Forces, such as their role, the different Services and recent campaigns in Iraq and Afghanistan. The students surveyed some of the characteristics unique to this population such as the importance of military symbols, the nuances of language, and different ranks. The session progressed to explore the implications of transition from the Armed Forces where veterans are faced with employment, finance, accommodation, and education challenges. An emphasis on communication skills was paramount, and embraced lessons from the US on how to open discussions with the AFC with questions such as "Would it be OK to talk about your military experiences?” (Veterans Health Administration, 2015).

The session progressed to examine the connection between military nursing with key nursing values (Department of Health, 2012) including excellence, caring, integrity and diversity, holism, patient-centeredness and ethical practice (Larson et al, 2013). To bring the session together the students were introduced to a vignette of a fictional military family called the Johnsons. The students would meet the Johnsons again in years two and three; in which time the fictional family age and their health and social care presentation change. At the end of an AFC educational session at the University of Cxxx, the first author informed the group of the qualitative study and then remained to address any personal questions. 
Semi-structured interviews were conducted by two third year students who had previously completed the same session and who had volunteered to be trained as co-researchers. The potential participants were informed that the interviews were on a voluntary basis, and that no action would be taken regarding anyone who did not come forward. Students were given time to reflect on their decision before confirming their interest to another independent lecturer via email. Twelve students volunteered and following informed consent, they conducted digitally recorded interviews between August 2018 and September 2018.

The interviews aimed to identify the strengths of the sessions, areas for development and afford a real-world insight into the students' lens of reality. An interview schedule was designed to enable a non-judgmental, open ended discussion focused on significant matters; with scope to explore unanticipated replies as they emerged. As this was the first time that the student co-researchers had undertaken research interviews, the inquiry was kept to four key questions, with an additional question where the participants could offer their own recommendations. The full schedule is at Table 1:

Table 1 around here.

\section{Ethics}

The questionnaires were anonymous and confidential, and students had the option of not answering the questions. Ethical approval was provided by the University of Cxxx Research Ethics Committee.

\section{Data Analysis}


Descriptive statistics were used throughout, predominately with frequency distributions and percentages, although there is cross-tabulation to identify differences in stratified groups, in particular between the two University sites. Quantitative data analysis was performed using IBM SPSS, version 22 (IBM Corp, 2017).

The qualitative interview data was analysed using a modified grounded theory methodology. Initial coding and then focused line by line coding identified words and phrases that related to students' views and perceptions regarding the AFC and educational content. This was crossreferenced to peer-review literature, with an emphasis on identifying emerging categories to inform analysis and generate concepts. All categories were used consistently (Mays \& Pope, 1995). This identification of fit and relevance facilitated the exploration of emerging themes enabled by theoretical sampling that was strategic, specific and systematic (Silverman, 2017). Interviews were continued and developed as new categories presented themselves and were sustained until the emerging categories were "saturated" (Charmaz, 2014). This indicated that the interviews no longer produced new theoretical insight (Silverman, 2017).

The authors utilised rigorous statistical tests on data from two independent sites to produce the numerical findings. Two authors scrutinised the data from the research interviews as a blind theoretical sampling exercise to ascertain comparators and differences. Quantitative and qualitative data was triangulated to improve the validity and reliability of the results. This being using different methods to collect data on the same topic, which in this instance utilised the results from the questionnaires to help inform the interview schedule and to then use the interview data to help provide insight into the questionnaire results. 


\section{Results}

This was a purposive sample of first year undergraduate nurses, of which 464 completed the questionnaire before the training started (pre-measurement) and 468 following the training (post-measurement). Differences in numbers were due to student's arriving late or leaving early. The sample was $92 \%(\mathrm{~N}=428)$ female and $8 \%(\mathrm{~N}=36)$ male. The mean age was 26 years $(\mathrm{SD}=7.596)$, the median was 24 years, and the mode was 19 years. (See Table 2: *pre-test).

Table 2 around here

To assess the effectiveness of the training, pre and post-tests were used to assess if the training increased knowledge and awareness of issues / attitudes regarding the AFC through a 20-item questionnaire. Results are summarised in Table 3 and Chart 1.

Table 3 around here

The training was effective in improving students' knowledge and awareness on the AFC, showing a significant increase in the number of correct responses following the training (Sum of correct responses Pre $\overline{\mathrm{x}}=7.96, \mathrm{SD}=2.477$; Post $\overline{\mathrm{x}}=15.69, \mathrm{SD}=2.854$ ), with strong effect sizes $(t(463)=42.793, p<0.001, d=2.89)$. The only question that showed no significant improvement was 'What does CO stand for?', probably because the response was common knowledge.

Chart 1 around here 
To assess student's satisfaction and views on a number of areas such as relevance, usefulness, and patient engagement; the authors included 11 questions in the post session questionnaire. Data is summarised in Table 4.

Table 4 around here

The following results are based on combining the agree / strongly agree responses and the disagree / strongly disagree responses.

Student satisfaction was high (overall questions $\overline{\mathrm{x}}=4.099, \mathrm{SD}=0.533$ ), with $93 \%(\mathrm{~N}=435)$ agreeing that the training was useful, $95 \%(\mathrm{~N}=446)$ felt that nurses should be aware of the healthcare needs care of the AFC, and $89 \%(\mathrm{~N}=412)$ indicated that it should be included in the undergraduate curriculum.

After the session, 51\% (N=236) reported that they would ask a new patient during an assessment if he / she was a member of the AFC and $18 \%(\mathrm{~N}=82)$ stated that they would not. Some $82 \%(\mathrm{~N}=371)$ reported that they would feel confident in engaging with the AFC, and $83 \%(\mathrm{~N}=381)$ agreed that transition from the AFC to civilian life was a stressor. There were $62 \%(\mathrm{~N}=285)$ that felt the AFC readily engages with civilian healthcare services and $15 \%$ $(\mathrm{N}=68)$ disagreed. Most of the students agreed that there is a requirement for prioritising the physical healthcare $(81 \%(\mathrm{~N}=377)$, and this increased for mental healthcare $(86 \%(\mathrm{~N}=395)$ for the AFC. There were $88 \%(\mathrm{~N}=405)$ indicating that there was a requirement for targeted care of the AFC and $85 \%(\mathrm{~N}=387)$ indicated that there should be a Armed Forces Champion who is the nominated organisational lead in every clinical facility. 
Single site results across five Likert points (strongly disagree to strongly agree) are in Table

5. There were small differences in the scoring depending on the site that would suggests that it was the topic rather than the lecturer that had the most impact.

Table 5 around here

Qualitative interviews lasted between 20 and 40 minutes. Qualitative coding led to the identification of 19 categories. These themes produced a story that reflected the interviewees' real-time perceptions and opinions leading to an evolving model comprising of four major clusters: the military community; student's identity, clinical engagement, and future practice. These themes were irrevocably linked to the role of the academic institute (or organisation) in promoting care of the AFC and the teacher's background and experience in delivering the lessons. This model is presented in Figure 1.

The model helps to deliver an explanation of the elements required for an educational session that will support students to gain awareness and promote motivation. Whilst respondents commented on their experiences, the findings are built on multiple rather than stand-alone testimonies. The student's comments are anonymised with students being referred to as AA, $\mathrm{BB}, \mathrm{CC}$ etc. No further information is provided.

Figure 1 around here

Teacher's Background and Experience. 
The 12 interviews were conducted with students from the University where the sessions were provided by the military veteran lecturer; and their comments indicated a positive experience:

“The experience that somebody's had shows when they're talking, and that is more beneficial cause people relate to them" (EE)

\section{Military Community}

What is a veteran?

The students were aware that "veteran" related to someone who had served in the military, but were unsure if the term related to indicate personnel who had served for a prolonged period or only to older veterans.

"You think of veterans as more likely being older, and someone who's been in the Army for a lot of years. Whereas I didn't realise it was literally a day" (AA)

Military Language and Symbols

The sessions helped the students understand military culture, and that the AFC could be identified from the language they shared. There was recognition of the importance of symbols, such as military medals, and how observing them in certain environments lead to an improved therapeutic relationship. 
Stressors and Transition

The students acknowledged the impact of serving in the British Armed Forces, and how stress on one member of the family was taxing for all. The discussions included the associated dangers of overseas deployments, and the resulting fear and worries for their families.

"Coming back and trying to fit back into like the father role, that his wife then didn't want to give him back, cause she'd got so used to doing that job herself and being on her own. So it does impact on family life" (GG)

This extended to recognition that transition from the Armed Forces was a particular period of high stress and vulnerability:

"You forget that once they come out of that environment that they are just one of us, and just expected to fit in and they are forgotten about as a community. It's hard to transition back, and it's not something that's greatly looked upon until we've been made aware of it" (BB)

Separate from Society

The session appeared to prompt students to be aware of the AFC as part of the wider society:

"They're around us all of the time but they are part of us. It's not a separate community” (DD) 


\section{Students Identity}

\section{Experience}

Whilst some students had experience of the AFC, for many this was their first acquaintance. The interviews provided insight to the reasons for the improved post test scores, with the quiz being a popular option.

"Quiz at the beginning, and having a guess at what you thought was the right answer to the multiple choice. Then as he's done the session, you're picking up the information and oh yeah, that was the answer to that one, it was really good" $(\mathrm{HH})$

Participant's' were proud in helping and engaging with the AFC.

"They're always there to protect us .... with the family of course, they did not choose to a member of the family with the veteran, but they have no choice, but I think they're doing great"' (CC)

Connecting with Students

Different sections appealed to different participants. The historical focus with military nurses such as Florence Nightingale and Mary Seacole helped develop a connection with the importance of caring for this community. Others referenced the fictional Johnson Family 
vignette and how they were looking forward to seeing how this advanced in years two and three.

"It's just made me a bit more aware of considering all the finer details of it really” $(\mathrm{HH})$

The participants indicated how the session could be improved, including better visual aids and animations. The students approved of the stepped approach of sessions in each of their three under-graduate years, and that the sessions would mature in context and deliverables. Others wanted a specific module with links to clinical placements;

"It's good that we do have three lectures throughout the three years, possibly bringing it in as module rather than just those three sessions. So it's more integrated into the course" ( $\mathrm{HH})$

\section{Clinical Engagement}

Confidence

Improved confidence may provide the momentum to assist this future nursing workforce to engage with the AFC in any clinical environment.

"I think I'll be more open now, I feel a more confident cause I've got a bit of background knowledge” (BB) 
Communication

The students highlighted the importance of engaging and communicating with veterans and their families.

"I'm much more likely that I would ask that sort of a question to clarify" (FF)

Reflecting

The students reflected on their clinical practice and previous encounters with veterans, and what could have been done differently:

"He had been a serving member of the forces and it made me think has anyone actually spoken to him and asked him questions?" (GG)

Empathy and Stigma

The interviews indicated an enhanced empathy, which stemmed from discovering and associating with the stressors faced by the AFC. Participants' recognised that veterans help seeking could be poor as they perceived themselves as weak, with MH shrouded in stigma, in a population that felt that non-veterans would not understand their experiences:

"People don't necessarily always want to talk, want to open up, and that's another thing that people need to understand" (AA) 
Mental Wellbeing

The students understanding of the empirical research behind military mental health was enlightening:

"There was a question of what you think affects them most health wise... a lot of people said post-traumatic stress disorder but the right answer was depression. That was quite an eye opener as well, which when you think about it afterwards, you can see why" (HH)

\section{$\underline{\text { Future Practice }}$}

Ownership

The students appeared to take ownership; in part determined through recognition that veterans form a heterogeneous population with differences based on age and gender:

"Especially the older population and a lot of them have spent most of their life in the military. They're the ones obviously we're treating now, and I think to ask obviously the question ... are you a veteran” (AA)

This extended to the family members they would encounter: 
"If you're dealing with the families as well I think to be educated a bit more on how to support them..... being able to give people that advice and support, it's not just the person themselves, it is the whole family" (AA)

Increased Knowledge, Insight and Awareness

Student's perceptions appeared to positively change as a result of increased knowledge, insight and awareness:

"This opened my eyes to what veterans and especially their families have to cope with...for instance with war and moving around from country to country" (EE)

This extended to delivering holistic care and the importance on listening to patient's narratives:

"They can feel quite isolated when they come out. So, try to gauge whether somebody has just come out of the military and then obviously try to work around, so that you can listen, that you kind of understand a bit about what they're going through" (II)

\section{A Better Nurse}

The student's revealed how individual patient pathways could be improved by connecting with veterans' support services and Charity organisations: 
"I didn't feel that their care would stop with me, and if they needed extra it would make me want to research who I would point them in the direction of. I would go that extra mile to help them" $(\mathrm{HH})$

Mandatory Module

Participants indicated that nursing care of the AFC should be included in the under graduate curriculum to improve their scope of practice as holistic clinical practitioners;

"If you put it in the curriculum, it's making people more aware and giving us as nurses the confidence to go and have that conversation with somebody rather than shy away from it. So definitely" (BB)

\section{Discussion}

Reports that veterans do not disclose detail of their military experiences because they presume clinicians "do not understand" has been accepted for too long. As such, the international concept of educating undergraduate nurses to provide care for the AFC of serving Armed Forces personnel, veterans and their families has gathered momentum (Flowers et al, 2017).

Overall, the intent to provide student nurses with an insight into the AFC to help them construct an understanding of the biopsychosocial needs aligned to the AFC's care, health and wellbeing seems to have been achieved. It is envisioned that the sessions will positively enhance the wellbeing of military veterans and challenging long standing issues aligned to 
stigma (Harding, 2017; Finnegan et al, 2018a), with the potential to promote research and community good will.

The results indicate knowledge acquisition, high levels of student satisfaction, and changes in beliefs and attitudes. Participants embraced the opportunity to appreciate the communication skills / language required for engaging with the AFC (Redmond et al, 2015). The findings indicate that an acquired awareness of the AFC and an understanding of the term veteran, which has been aligned to improving and promoting the physical and mental wellbeing of the AFC. The participants' reference to reflective practice can help shape better nursing outcomes (Caldwell \& Grobbel, 2013), and in this study the students ruminated on previous dealings with veterans in clinical practice and have advocated a positive change in practice. By stimulating critical thinking, the students are empowered to focus on the individual and family needs by encouraging a problem-solving approach (Redmond et al, 2015).

This initiative has been influenced by global developments (Magpantay-Monroe, 2017; Morrison-Beedy, Passmore \& D'Aoust, 2015;), and aat the University of Cxxx, the sessions are now mandated within nursing and social work under-graduate programmes. This initiative and educational model have enabled the authors to work with the UK's programme for educating Primary Healthcare Doctors (Royal College of General Practitioners (RCGP), 2019), including their free online module (RCGP, 2018). The RCGP training compliments the authors' initiative, and the online material has been shared across both platforms.

From a conception in 2016, this two-year project has witnessed significant developments, although there remain obstacles to address. Some institutions do not contain academics with sufficient knowledge of the AFC to deliver these sessions, although this can be addressed 
with a veteran specific train the trainer's course (Brock et al, 2013). There is also scope to embrace veterans into the nursing workforce and mirror the opportunities offered by UK Universities in supporting wounded injured and sick personnel into employment (RFEA, 2019).

The intent was to embrace advancing technologies and build online eLearning which are at least equivalent to traditional education (George et al, 2014), and the authors plan to augment our growing online materials to provide students with access to e-lectures and discussion groups. This freely available educational material also presents an opportunity to share information with the wider clinical workforce, welfare agencies and AFC beneficiaries (University of Cxxx, 2019). An off-shoot benefit has been a joint workshop with the Royal British Legion (RBL); the UK's largest veteran's charity. These lectures were filmed as an additional resource and pooled with recorded presentations from leading international experts. Students will now spend a minimum of one day with the RBL, with an option for a six-week elective.

The initiative has grown to into an international partnership in the USA and Australia (Finnegan et al, 2018b), thereby providing insight and visibility of overseas initiatives. As such, the authors will assess opportunities to utilise a USA method of simulation for teaching veterans care (Anthony et al, 2012).

\section{Limitations}

The evaluation was on just two sites. It is recognised that course resources could be significantly improved, which would enhance the sessions and potentially the outputs. Only 12 students were included in the qualitative element of taped interviews although the authors 
believe that saturation was accomplished. A significant minority indicated in the quantitative analysis that they disagreed that the sessions were required; yet they clearly did not volunteer to be interviewed and therefore the results do not capture their opinions and perceptions.

\section{Conclusion}

The empirical results for this original UK initiative indicate that the authors are heading in the right direction, with findings signifying that students would like AFC sessions embedded into the UK BNurs degree curriculum. The educational model in Figure 1 is transferable to other disciplines and environments and provides the foundation for development.

The authors are mindful of overstating the impact that one session will have on long-term deliverables, however encouraging the results may seem. Also, whilst recognising that the study's online material can be used by other Universities and interested parties, it is unquestionable that better resources would enhance the course content and potentially the outputs.

The findings from the research has provided a foundation to develop the sessions, enhance the IT delivery, build an online module and deliver a train the trainers course. The intent is to work collaboratively to ensure the momentum generated within this initiative is maintained, whilst exploiting sessional content that is dynamic and shaped by student evaluations and lessons learnt from international collaborations. The growth in this knowledge will lead to increased support through partnerships, funding, access to resources, college promotion, and community good will. This may help transform traditional educational models to new ways of working and thereby lead to better care for the AFC. 
Conflict of Interest - No conflict of interest has been declared by the authors. 


\section{References}

Allen, P. E., Armstrong, M. L., Conard, P. L., Saladiner, J. E., \& Hamilton M. J. (2013).

Veterans' health care considerations for today's nursing curricula. The Journal of Nursing

Education, 52(11), 634-640. doi:10.3928/01484834-20131017-01

Anthony, M., Carter, J., Freundl, M., Nelson, V., Wadlington, L. (2012). Using simulation to teach veteran-centered care. Clinical Simulation in Nursing, 8(4), 145-150.

doi:10.1016j.ecns.2010.10.004

Ashcroft, M. (2014). The Veterans' Transition Review Report. Available at:

www.veteranstransition.co.uk/vtrreport.pdf 07 July 2019

Ashcroft M. The veterans' transition review - Third Follow Up Report. Crown 2017. http://www.veteranstransition.co.uk/vtr3 followup_2017.pdf (accessed 20 Aug 2019).

Australian Government. (2018). Australian Institute of Health and Welfare (AIHW). A Profile of Australia's Veterans: How Many Veterans are there in Australia. Available at: https://www.aihw.gov.au/getmedia/1b8bd886-7b49-4b9b-9163-152021a014df/aihw-phe235.pdf.aspx?inline=true Accessed 07 July 2019

Batham, D., Finnegan, A. P., Kiernan, M., Wall, C. Simpson, R. (2012). Factors affecting front line casualty care in Afghanistan. Journal of the Royal Army Medical Corps, 158(3), 173-180. http://dx.doi.org/10.1136/jramc-158-03-05 
Bisset, A., \& Chesson, R. (2000). Is this satisfaction survey satisfactory? Some points to consider in their planning and assessment. Health Bulletin, 58(1) 45-52.

Brock, D., Bolon, S., Wick, K., Harbert, K., Jacques, P., Evans, T., Abdullah, A., Gianola, F.J. (2013). The military veteran to physician assistant pathway. Building the primary care workforce. Academic Medicine: 88(12), 1890-1894. doi: 10.1097/ACM.0000000000000011

Caldwell, L \& Grobbel, C (2013). The importance of reflective practice in nursing. International Journal of Caring Sciences, (6)3, 319-326.

Coll, J. E., Weiss, E. L., Yarvis, J. S. (2011). No one leaves unchanged: Insights for civilian mental health care professionals into the military experience and culture. Social Work in Health Care, 50(7). 487-500. doi:10.1080/00981389.2010.528727

Charmaz, K. (2014). Constructing grounded theory. A practical guide through qualitative analysis. $2^{\text {nd }}$ Edn. Sage, London.

Conard, P. L., Allen, P. E., Armstrong M. L. (2015). Preparing staff to care for veterans in a way they need and deserve. Journal of Continuing Education in Nursing, 46(3), 109-118. doi:10.3928/00220124-20150220-15

Crawford, M., Sharpe, D., Rutter, D., Weaver, T. (2009). Prevention of suicidal behaviour among Army personnel: A qualitative study. Journal of the Royal Army Medical Corps, 155(3), 203-207. http://dx.doi.org/10.1136/jramc-155-03-07 
Czaja, R., Blair, J. (2005). Designing surveys: A guide to decisions and procedures.

Thousand Oaks, CA: SAGE.

Department of Health. (2012). Compassion in Practice. Nursing, Midwifery and Care Staff.

Our Vision and Strategy. London, United Kingdom: NHS Commissioning. Available at: https://www.england.nhs.uk/wp-content/uploads/2012/12/compassion-in-practice.pdf Accessed 07 July 2019

Department of Veterans Affairs. (2019). National Centre for Veteran Analysis and Statistics. Available at: https://www.va.gov/vetdata/ Accessed 17 Oct 2019

Elliott, B. (2018). Civilian nurses' knowledge, confidence and comfort caring for military veterans: Survey results of a mixed-methods study. Home Healthcare Now, 36(6), 356-361. doi: 10.1097/NHH.0000000000000698

Elliott, B., Patterson, B (2017). Joining forces: The status of military and veteran health care in nursing curriculum. Journal of Professional Nursing, 33(2), 145-152.

DOI: 10.1016/j.profnurs.2016.06.006

Finnegan, A. P., Finnegan, S., Thomas, M., Deahl, M., Simpson, R., Ashford, R. (2014). The Presentation of depression in the British Army. Nurse Education Today, 34(1), 83-91. doi:10.1016/j.nedt.2013.02.020

Finnegan, A. P., Finnegan, S. E., McKenna, H., McGhee, S., Ricketts, L., McCourt, K., Warren, J., Thomas, M. (2016a). Characteristics and values of a British military nurse. 
International implications of war zone qualitative research. Nurse Education Today, 36, 8695. doi:10.1016/j.nedt.2015.07.030

Finnegan, A. P. (2016b). The biopsychosocial benefits and shortfalls for armed forces veterans engaged in archaeological activities. Nurse Education Today, 47, 15-22. doi:10.1016/j.nedt.2016.03.009

Finnegan, A. P., McGhee, S., Leach, J. (2017). Educating nurses to provide better care for the military veteran and their families. Nurse Education Today, 54, 62-63. doi:10.1016/j.nedt.2017.04.014

Finnegan, A.P., Jackson, R., Simpson, R. (2018a). Finding the forgotten. Motivating military veterans' to register with a primary healthcare practice. Military Medicine. 183(11-12) e509e517. DOI: 10.1093/milmed/usy086

Finnegan, A., Currie, J., Ryan, T., Steen, M. (2018b). Nurse education and the military veteran. Australian Nursing and Midwifery Journal, 25(10), 38.

Flowers, M., Cadavid, M., Galindo-Ciocon, D., Munoz, A.P., \& Nash, D. (2017). Impact of veteran-centric prepared nurses on veteran outcomes. International Journal of Nursing, 4(1). 13-18 DOI: $10.15640 /$ ijn.v4n1a3 
George, P.P., Papachristou, N., Belisario, J.M., Wang, W., Ward, P.A., Cotic, Z., Rasmussen, K., Sluiter, R., Riboli-Sasco, E., Tudor Car, L., Musulanov, E.M., Molina, J.A., Heng, B.H., Zhang, Y., Wheeler, E.L., Al Shorbaji, N., Majeed, A., Car, J. (2014). Online eLearning for undergraduates in health professions: A systematic review of the impact on knowledge, skills, attitudes and satisfaction. Journal of Global Health, 4(1): 010406.

doi: 10.7189/jogh.04.010406

Gov UK (2018). UK armed forces mental health annual statistics: index. Statistical information on mental health among the UK armed forces. 21 June. Available at: https://www.gov.uk/government/collections/defence-mental-health-statistics-index Accessed 07 July 2019

Harding, S. (2017). Self-stigma and veteran culture. Journal of Transcultural Nursing, 28 (5), 438-444. doi.org/10.1177/1043659616676319

Hines, L, A., Goodwin, L., Jones, M., Hull, L., Wessely, S., Fear, N. T., Rona, R. J. (2014). Factors affecting help seeking for mental health problems after deployment to Iraq and Afghanistan. Psychiatric Services, 65, 98-105. doi:10.1176/appi.ps.004972012 Hynes, C., Thomas, M. (2016). What does the literature say about the needs of veterans in the areas of health? Nurse Education Today, 47, 81-88.

http://dx.doi.org/10.1016/j.nedt.2016.08.001

IBM Corp. (2017). IBM SPSS Statistics for Windows, Version 25.0. Armonk, NY: IBM Corp.

International Council of Nurses. (2014). Definition of Nursing. Available at: 
https://www.icn.ch/nursing-policy/nursing-definitions Accessed 07 July 2019

Iversen, A. C., van Staden, L., Hacker Hughes, J., Greenberg, N., Hotopf, M., Rona, R. J., Thornicroft, G., Wessely, S., Fear, N. T. (2011). The stigma of mental health problems and other barriers to care in the UK Armed Forces. BMC Health Services Research, 11(1) 31. doi:10.1186/1472-6963-11-31

Larson, J., Brady, M., Engelmann, L., Perkins, I., Shultz, C. (2013). The formation of professional identity in nursing. Nursing Education Perspectives, 34(2) 138. http://dx.doi.org/10.1097/00024776-201303000-00016

Magpantay-Monroe, E. R. (2017). Integration of military and veteran health in a psychiatric mental health BSN curriculum: A mindful analysis. Nurse Education Today, 48, 111-113. doi:10.1016/j.nedt.2016.09.020

Mays, N., Pope, C. (1995). Qualitative research: Rigour and qualitative research. British Medical Journal, 311, 109-112. doi: https://doi.org/10.1136/bmj.311.6997.109

McMillan L. R., Crumbley, D., Freeman, J., Rhodes, M., Kane, M., Napper, J. (2017). Caring for the Veteran, military and family member nursing competencies: Strategies for integrating content into nursing school curricula. Journal of Professional Nursing, 33(5), 378-386. doi:10.1016/j.profnurs.2017.06.002

Miltner, R. S., Selleck, C. S., Moore, R. L., Patrician, P. A., Froelich, K. D., Eagerton, G. S., Harper, D. C. (2013). Equipping the nursing workforce to care for the unique needs of veterans and their families. Nurse Leader, 11(5), 45-48. doi:10.1016/j.mnl.2013.05.013 
Ministry of Defence (2008). The nation's commitment: cross-government support for our armed forces, their families and veterans. Available at:

https://www.gov.uk/government/publications/the-nations-commitment-cross-governmentsupport-for-our-armed-forces-their-families-and-veterans Accessed 07 July 2019

Ministry of Defence (2015). 2010 to 2015 government policy. Armed Forces Covenant. Available at: https:// www.gov.uk/government/publications/2010-to-2015-governmentpolicy-armed-forces-covenant/2010-to-2015-government-policy-armed-forces-covenant Accessed 07 July 2019

Ministry of Defence (MoD). Annual Population Survey: UK Armed Forces Veterans residing in Great Britain, 2017. MoD 2019.

https://assets.publishing.service.gov.uk/government/uploads/system/uploads/attachment_data /file/774937/20190128__APS_2017_Statistical_Bulletin___OS.pdf (accessed 17 Oct 2019).

Mobbs, M.C., Bonnanno, G.A. (2018). Beyond war and PTSD: The crucial role of transition stress in the lives of military veterans. Clinical Psychology Review, 59, 137-144. doi.org/10.1016/j.cpr.2017.11.007

Morrison-Beedy, D., Passmore, D., D'Aoust, R. (2015). Military and veteran's health integration across missions: How a college of nursing "joined forces." Nursing Outlook, 63(4), 512-520. doi: 10.1016/j.outlook.2015.05.004

Moss, J. A., Moore, R. L., Selleck C. S. (2015). Veteran competencies for undergraduate 
nursing education. Advances in Nursing Science, 38(4), 306-316. doi:

10.1097/ANS.0000000000000092

National Health Service England. (2017). Next steps on the NHS Five Year Forward View:

17,500 forces veterans and service personnel to benefit from $£ 9 \mathrm{~m}$ investment in new and improved NHS mental health services. Available at:

https://www.england.nhs.uk/2017/04/next-steps-on-the-nhs-five-year-forward-view-veterans Accessed 07 July 2019

National Health Services Choices. (2018a). NHS healthcare for veterans. Available at: http://www.nhs.uk/NHSEngland/Militaryhealthcare/veterans-familiesreservists/Pages/veterans.aspx Accessed 07 July 2019.

National Health Services Choices. (2018b). Healthcare for the armed forces community. Available at:

http://www.nhs.uk/NHSEngland/Militaryhealthcare/Pages/Militaryhealthcare.aspx Accessed 07 July 2019

Oppenheim, A.N. (1992). Questionnaire Design, Interviewing and Attitude Measurement. London, United Kingdom: Heinemann.

Royal College of General Practitioners (2018) Military Veterans. At:

http://elearning.rcgp.org.uk/course/info.php?id=289 Accessed 07 July 2019

Royal College of General Practitioners (2019) Veterans' Healthcare Needs. At: 
https://www.rcgp.org.uk/policy/rcgp-policy-areas/veterans-healthcare-needs.aspx Accessed 07 July 2019

Redmond, S.C., Wilcox, S.L., Campbell, S., Kim, A., Finney, K., Barr, K., Hassan, A.M. (2015). A brief introduction to the military workplace culture. Work, 50(1), 9-20.

RFEA (2019). Universities in Support of Wounded, Injured and Sick Service Personnel. Available at: https://www.rfea.org.uk/our-programmes-partnerships/unswis/ Accessed 07 July 2019.

Rossiter, A. G., Patrician, P. A., Dumas, M. A., Ling, C. G., Johnson, H. L., Wilmoth, M. C. (2018). I serve 2: Identifying and caring for military children in civilian primary care settings. Journal of the American Association of Nurse Practitioners, 30 (11), 619-620. doi: 10.1097/JXX.0000000000000084

Silverman, D. (2017). Doing qualitative research. (5th Ed.). London, United Kingdom: Sage United States Department of Labor. (2014). Bureau of Labor statistics. Available at: http://www.bls.gov/news.release/vet.toc.htm Accessed 07 Jult 2019 University of Cxxx (2019). Westminster Centre for Research in Ageing, Mental Health and Veterans. Academia. Available at: https://www1.chester.ac.uk/westminster-centre-researchand-innovation-veterans-wellbeing/academia Accessed 07 July 2019 
Veterans Health Administration Office of Academic Affiliations. (2015). Military health history: Pocket card for health professions trainees and clinicians. Available at:

http://www.va.gov/oaa/archive/Military-Health-History-Card-for- print.pdf Accessed: 07 July 2019

Wessely, S (2005) : Risk, psychiatry and the military. British Journal of Psychiatry; 186(6):

459-66. DOI: 10.1192/bjp.186.6.459

Yousaf, O., Grunfeld, E.A., Hunter, M.S. (2015) A systematic review of the factors associated with delays in medical and psychological help-seeking among men, Health Psychology Review, 9:2, 264-276, DOI: 10.1080/17437199.2013.840954 